\title{
A comparison of some fixed point iteration procedures by using the basins of attraction
}

\section{Gheorghe Ardelean, Ovidiu Cosma and LAszlo BAlog}

\section{ABSTRACT.}

Several iterative processes have been defined by researchers to approximate the fixed points of various classes operators. In this paper we present, by using the basins of attraction for the roots of some complex polynomials, an empirical comparison of some iteration procedures for fixed points approximation of Newton's iteration operator. Some numerical results are presented. The Matlab $m$-files for generating the basins of attraction are presented, too.

\section{REFERENCES}

[1] Agarwal, R. P., O'Regan, D. and Sahu, D. R., Iterative construction of fixed points of nearly asymptotically nonexpansive mappings, Journal of Nonlinear and Convex Analysis, 8 (2007), No. 1, 61-79

[2] Ardelean, G., A comparison between iterative methods by using the basins of attraction, Appl. Math. Comput., 218 (2011), 88-95

[3] Berinde, V., Iterative Approximation of Fixed Points, 2nd edn. Springer, Heidelberg, 2007

[4] Berinde, V., On the convergence of the Ishikawa iteration in the class of quasi-contractive operators, Acta Mathematica Universitatis Comenianae, 73 (2004), No. 1, 119-126

[5] Berinde, V., Picard iteration converges faster than Mann iteration for a class of quasi-contractive operators, Fixed Point Theory Appl., 1 (2004), 97-105

[6] Berinde, V., Khan, A. R. and Păcurar, M., Analytic and empirical study of the rate of convergence of some iterative methods, Rev, Anal. Numér. Théor. Approx., 44, (2015), (in press)

[7] Chugh, R. and Kumar, S., On the Stability and Strong Convergence for Jungck-Agarwal et al. Iteration Procedure, IJCA, (0975 8887) 64, (2013), No. 7

[8] Gdawiec, K., Kotarski, W. and Lisowska, A., Polynomiography with Non-standard Iterations, WSCG 2014 Poster Papers Proceedings, 21-26

[9] Ishikawa, S., Fixed Points by a New Iteration Method, Proceedings of the American Mathematical Society, 44 (1974), No. 1, 147-150

[10] Khan, S. H., A Picard-Mann Hybrid Iterative Process, Fixed Point Theory and Applications, (2013), Article ID $69,10 \mathrm{pp}$.

[11] Kalantari, B., Polynomiography: From the Fundamental Theorem of Algebra to Art, Leonardo 38 (2005), No. 3 , 233-238

[12] Mann, W. R., Mean Value Methods in Iteration, Proc. Amer. Math. Soc., 44 (1953), 506-510

[13] Noor, M. A., Kassias T. M. and Huang, Z., Three-step iterations for nonlinear accretive operator equations, J. Math. Anal. Appl., 274 (2001), 59-68

[14] Olaleru, J. O., A comparison of Picard and Mann iterations for quasi-contraction maps, Fixed Point Theory, 8 (2007), No. 1, 87-95

[15] Picard, E., Mémoire sur la théorie des équations aux dérivées partielles et la méthode des approximations successives, Journal de Mathématiques Pures et Appliqu, ées 6(4) (1890), 145-210

Received: 04.06.2016; In revised form: 21.07.2016; Accepted: 22.07.2016

2010 Mathematics Subject Classification. 47H10, 65H05.

Key words and phrases. Fixed point, iteration procedure, Newton's method, number of iterations, convergence, basin of attraction.

Corresponding author: Gheorghe Ardelean; ardelean_g@cunbm.utcluj.ro 
[16] Rus, I. A., Picard operators and applications, Sci. Math. Jpn., 58 (2003), 191-219

[17] Rus, I. A., Fixed Point Structure Theory, Cluj Univ. Press., 2006

[18] *** www.mathworks.com

TECHNICAL UNIVERSITY OF CLUJ-NAPOCA

NORTH University CENTER AT BAIA MARE

DePARTMENT OF MATHEMATICS AND COMPUTER SCIENCE

VICTORIEI 76, 430122, BAIA MARE, ROMANIA

E-mail address: ardelean_g@cunbm.utcluj.ro; ovidiu.cosma@yahoo.com balog_58@yahoo.com 